\title{
TECHNOLOGY OF TRANSFER OF PROFESSIONAL SKILLS TO KNOWLEDGE, SKILLS AND PROFICIENCIES
}

\author{
Munavvar Abdulaevna Sheralieva \\ Lecturer, Termez State University, Uzbekistan
}

\section{ABSTRACT}

This article highlights the essence of the technology of improving the professional skills of students, working on the quality of their important professional knowledge, skills and abilities.

KEYWORDS:- Teacher, student, pedagogy, didactics, knowledge, skill, qualification, activity, technology, mastery, exercise, practical activity, personal character, professionalism, quality, efficiency.

\section{INTRODUCTION}

The Action Strategy on the five priority areas of development of the Republic of Uzbekistan, adopted on the direct initiative and under the leadership of the President of the Republic of Uzbekistan Sh.M.Mirziyoev, has launched a new stage of development in the republic. The practical results of this process are clearly reflected in all spheres of our lives today, and most importantly, in the minds, aspirations and actions of our people.

Particular attention is paid to the improvement of the education system, which is one of the priorities of the fourth strategy of action - the development of the social sphere.

In his meetings and speeches at various meetings held during his visit to each region, the head of our state emphasizes the need to raise the issues of upbringing a harmoniously developed generation, young people to lead a healthy lifestyle as a topical issue on the agenda. As the President said: "If we do not bring up our children properly, if we are not aware of their behavior and mood every day, every minute, they will be deprived of knowledge and skills. If we don't train, if we don't find a decent job, we will lose this deposit. ${ }^{\mathbf{1}}$

The laws of the Republic of Uzbekistan "On Education" and "On the National Training Program" also define the tasks of training highly qualified specialists in our country who can meet the requirements of world standards2. In` particular, the goal of the National Training Program is to radically reform the education system, to free it from the ideological stereotypes

Decree of the President of the Republic of Uzbekistan "On the strategy of further development of the Republic of Uzbekistan." Tashkent, February 7, 2017 PF - 4947. 
of the past, to create a national system of training qualified personnel at the level of developed democracies that meets high moral and ethical standards3.

One of the current challenges of the period is to improve the professional skills of students, to develop in them important professional knowledge, skills and competencies.

Therefore, it is important to work on the quality of knowledge, skills and competencies that students need to learn in the process of teaching and learning.

Acquisition of knowledge, skills and competencies characterizes the basis of the educational process and occurs as its basis, an important condition. Accordingly, these concepts are of fundamental importance in the theory and practice of pedagogy. The content of knowledge, skills and abilities and aspects of their formation are theoretically substantiated in a wide range of literature on psychology, didactics, private methodology and practical training of students. No matter how clearly these concepts are defined, these concepts need to be studied in more depth and theoretically grounded in all respects.

In the pedagogical literature, the concept of "knowledge" is usually evaluated by people as a product of knowledge of existing knowledge and phenomena, the laws of nature and society. (Ped. Encycl., 1965).

2 .Mirziyoev Sh.M. Let us be more united and work resolutely for the fate and future of our country. // "Xalq so'zi" newspaper., June 16, 2017.

3. Laws of the Republic of Uzbekistan "On Education" and "On the National Training Program". -T .: "Sharq", 1997.
Such a definition mainly serves to reveal the philosophical aspect of knowledge. In didactic theory, the concept of "knowledge" is mainly interpreted in two ways: the knowledge that students need to acquire, as well as the knowledge that they have acquired and applied in the process of practical activities, which have become personal qualities.

The first definition we give above defines the content of education. This knowledge is of an adequate nature and represents a proven material existence, in the life of society. Knowledge is not a rigid, unchanging phenomenon, but throughout the historical development of the life of society, knowledge is also constantly evolving, being defined, deepened, and sometimes subjected to significant changes and improvements. In pedagogical theory, the scientific content of education is ensured only by taking into account this factor, which is inherent in knowledge. The knowledge provided in the course of the subject can be divided into two groups: scientific knowledge that represents the basics of science in the appropriate form, and scientific information in the form of information that varies in terms of relevance and stability. Scientific data usually occurs as a product of theories. The regular accumulation of this knowledge leads to an increase in the amount of information in the deductive system that represents a particular state of modern science, but does not make any changes to the knowledge system that forms the basis of this science. In this case, only a fraction of the new data serves to change the basic tenets of scientific theory. In this case, the more generalized the knowledge, the more stable it will be.

Naturally, in the process of managing students' learning activities, the teacher not only provides them with fundamental knowledge of a particular subject, but also provides current 
CURRENT RESEARCH JOURNAL OF PEDAGOGICS 2(10): 175-181

October 2021 DOI: https://doi.org/10.37547/pedagogics-crjp-02-10-31

ISSN 2767-3278

(C)2021 Master Journals

\section{Crossref doi) google}

Accepted $26^{\text {th }}$ October, 2021 \& Published $31^{\text {th }}$ October, 2021

information that enriches this knowledge, demonstrates the various connections and relationships between them, reflects the everincreasing needs of society and the individual. should.

Knowledge should cover the main aspects being studied in a logical sequence, be interconnected, and reveal all the important aspects of each concept being studied, i.e., be consistent. The main quality of the acquired knowledge is their level of comprehensibility. They are manifested in the ability of the student not only to describe objects and events, but also to substantiate the facts being studied, to draw conclusions. Knowledge must also be perfected to serve the content and scope of the objects and events being studied.

The acquired knowledge serves as the basis for the skills and competencies to be developed. There are a number of perspectives on the content and interrelationships of skills and competencies. From the traditional point of view that exists in didactics, the skill is formed before the skill, and the skill becomes the skill as a result of the exercise. For example, in the "Pedagogical Encyclopedia" (1968) skill is defined as "the ability to effectively perform the characters appropriate to the conditions in which they work"; skills will be both practical and theoretical in nature. In the same Pedagogical encyclopedia "Qualification is defined as a high-level action", at this stage the actions are automated, mental control is reduced to a degree. Qualification is the ability to perform a practical activity so quickly that it is as if the action is being performed spontaneously."

In the book "Psychology", edited by AA Smirnov, edited by AN Leont'ev, skills are described as "a method of action strengthened by exercise", and skills "do not require exercises that allow to achieve a stable and orderly level of performance." (M., 1962. pp. 439, 446-447).

MA Danilov writes that skills are knowledge of actions, and skills represent some automated part of movement. / Learning process // Basic didactic edited by BPEsipov M.1967, pages 197$198 /$.

The Recommendation for Vocational Schools defines: "Skill is a type of activity in which actions are performed with sufficient thought and automation; and skill represents automated action. "Any planned operation is very thoughtless." (M.I.Eretskiy, E.S.Porotskiy. Proverka znaniy i umeniy i navыkov uchashchixsya teknikumov. M 1978. pp. 11-12).

According to KK Platonov, "Skills are formed on the basis of previously formed knowledge and skills; Qualification is the performance of a purposeful activity by automating the actions that make it up, without special attention to it, but under mental control.". According to KK Platonov, "Skills are formed on the basis of previously formed knowledge and skills; Qualification is the automation of the actions that make it up in the course of a purposeful activity, without special attention to it, but under mental control. The scholar writes: "Any skill, including knowledge and skills, is formed on the basis of existing knowledge and skills, reshaping their missing elements in new conditions. Олим шундай ёзади: “Any skill, including knowledge and skills, is formed on the basis of existing knowledge and skills, reshaping their missing elements in the new environment. (Psychology. M., 1977. pp. 80-82). The literature on psychology states the following about skills and competencies: "The ability of a person to perform purposeful actions in a partially automatic manner is called competence." Also, the knowledge and skills acquired by the subject with the term "skill" represent a system of pedagogical and psychological actions necessary for the proper management of activities. 
(Psychology. Edited by A.V.Petrovsky. M., 1986.107,116 pages).

In summary, "Ability is the ability to perform actions effectively; skill is knowledge in action; ability to perform actions to a certain extent; skills are a way of performing an action in new conditions; the ability is to master complex systemic mental and practical actions".

Skills are defined as follows: "A skill is a set of actions with a high degree of maturity; skills are formed on the basis of knowledge and skills "[8, 97].

From the examples given, it is clear that there are different views on the content and essence of the concepts of "skill" and "qualification".

Given the diversity of human activity and the nature of the skills and abilities it uses, the concepts of "skills" and "qualifications" are used in didactics in pedagogical, psychological and socio-historical senses. This is explained by the fact that, firstly, the student is the object of psychological pedagogical influence, as a result of which he acquires knowledge, skills and abilities, and secondly, gradually becomes a socially significant person under the influence of acquired knowledge, skills and abilities. At the same time, knowledge, skills and abilities serve to meet a person's needs.

The skill is initially performed under practical mental control. As the conditioned reflector connections are strengthened, this control decreases. Accordingly, it can be said that the ability in human activity is realized under a certain degree of mental control. This represents the psychological pedagogical essence of the skill, in turn. As a result of exercises in individual movements, a situation arises in which no mental control is required in the performance of the action, the activity is performed automatically, as a result of which the skill becomes a skill.

The psychological basis of a skill is expressed, on the one hand, in the purpose of the activity, and, on the other hand, in its interaction with the initial state of the activity.

Complex skills are formed as a result of the addition of new ones to existing skills and competencies in a person. For example, the ability to drive a car, in particular to open the car door, start the engine, depress and release the brakes, clutches, accelerator pedals, the number of extensions is improved as a result of the addition of many elementary skills and connections, such as switching and disengaging, connecting headlights, steering wheel steering. As conditioned reflex connections become stronger, some skills quickly become skills.

Skills are formed as a superstructure of qualifications according to their origin. This situation is determined by the diversity of human actions, which require a creative approach to the environment. The result of analysis and synthesis, in which each new skill is constantly evolving, is the addition of new ones to existing knowledge; and skill is the result of many repetitions of the same action.

- Thus, skill and competence is a sociohistorical concept that develops under certain conditions and at a certain rate, using specific tools. Social practical activity for students will be available as a system of demanding and purposeful actions.

In particular, general labor and professional skills of students are formed at the following stages:

- $\quad$ - At the initial stage of skills development, students are explained the procedure for the action to be mastered. While knowing how to perform an action may not ensure its full performance, it will be necessary for skill formation. Acquaintance with the student's actions takes place until he learns it, that is, until a skill is formed. But a superficial acquaintance 
with the task of action and its description is not sufficient for the formation of competence. Execution of actions should be mastered deeply and firmly under the guidance of the teacher. In the early stages of action learning, the educator's task is defined by explaining the sequence of actions, demonstrating their practical significance, deepening and systematizing students 'knowledge, in other words, giving him or her a clear understanding of the exercise description and purpose;

- - The next, the second stage is the formation of the rules that form the basis of the formation of skills and the acquisition, restoration of knowledge;

- The third stage - the actions that can be stagnant during the performance of the next exercise, demonstrate patterns that eliminate the initial errors. How the teacher should perform this or that action shows the difficulties the student faces in the work process;

- The fourth stage is determined by the practical mastery of the action, the formation of skills. Skill formation takes place during an exercise aimed at improving the way a movement is performed. In doing so, the student begins to consciously use the rules. At this point, it is especially important to analyze actions, study errors, and prevent them;

- Finally, the last fifth stage - consists of exercises performed independently and systematically. As these exercises increase in complexity, attention is paid to their diversity, so that the activity is interesting and in most cases has a creative description.

The distribution of exercises over time will be important in the formation of skills. The result of exercise performed continuously for a long time may not give the expected effect due to fatigue. This means that exercise should be replaced by other types of work and rest.
The breaks between them also have a significant effect on the effectiveness of the exercises. Excessively long breaks reduce the effectiveness of the exercises and increase the time spent on them. Psychological research has shown that the most convenient distribution of exercises is as follows: frequent repetitions at the beginning of training and gradually lengthening their interval.

The level of skill formation can be determined by the speed and accuracy of the actions performed. Stability of action outcomes is also an important factor. Highly formed skills are determined not by individual success in performing actions, but by consistently achieving high results. If the good results of an action are maintained even when it is incorporated into a new, more complex system of actions, it is an indication of a fully formed skill, and is another important criterion of its formation.

During the exercises, the skills become more flexible, that is, the ability to choose the appropriate style according to the conditions of the movement is formed. In training workshops, students have almost no time to perform learning exercises to develop the required skills.

Due to the large number of specific types of work, it is not possible to equip university students with all kinds of professional skills and competencies. There is no need for that either. Skills are migratory. Accordingly, a skill previously acquired from one type of activity makes it somewhat easier to master another type of similar activity. Therefore, students should be equipped with the skills and competencies related to the most general and typical types of activities. The condition for the transfer of skills is determined by the psychological structure, content and methods of implementation of activities. For example, when cutting and sawing metal with a saw, there is a pressure action on it. In performing them, the student position, instrument grip, and movement control are the 
same. The percussive movement is the main in cutting, splitting, straightening, bending, sharpening with a chisel, all of which have the same grip, posture, general control of movements. There are also similarities in the performance of many other actions. The scientific and technical bases of modern developing production bring the work of workers in various fields closer. Accordingly, an understanding of their mastery is important in the transfer of skills. In mastering a particular skill, the student learns not only the appropriate actions, but also the methods and ways that will lead him to success. In his next activity, he will use his previous experience and try not to repeat the mistakes made, and as a result, it will be easier to learn new skills.

Thus, considering the educational process from the point of view of the activity of the theory of education, we believe that it is necessary to transfer all educational work in public education to the direction of pedagogical technology, to seriously justify each element of its voluntary nature in school practice.

\section{Conclusion}

- In conclusion, we present a generalized scheme of implementation of pedagogical technology. We used it as a methodological basis in conducting experiments:

- Analysis of future activities of students, setting goals and objectives to be addressed in the educational process;

- Development of educational content on the use of teaching aids in the development of general labor and professional skills;

- Determining the place of time for students to master the technology of using educational tools in the curricula of higher education institutions;

- Development of a system of exercises aimed at developing skills and abilities in students;

- Development of a system of objective control and testing related to quality control of students' knowledge, skills and abilities;

- Practical testing of the developed pedagogical technology and its application in the educational process.

\section{REFERENCES}

1. Decree of the President of the Republic of Uzbekistan "On the strategy of further development of the Republic of Uzbekistan". Tashkent, February 7, 2017 PF - 4947

2. 2.Mirziyoev Sh. Let us be more united and work resolutely for the fate and future of our country. // People's speech, June 16, 2017.

3. Decree of the President of the Republic of Uzbekistan "On the strategy of further development of the Republic of Uzbekistan." Tashkent, February 7, 2017 PF - 4947.

4. Laws of the Republic of Uzbekistan "On Education" and "On the National Training Program". -T .: "Sharq", 1997.

5. 5.Yuldashev J.G'., Usmonov S.A. Fundamentals of pedagogical technology. -T .: Teacher, 2004. - $236 \mathrm{p}$.

6. 6.Muslimov N.A. and b. Methods of teaching labor education and career guidance: Textbook. -T., 2014. - 292 p.

7. 7.0chilov M. New pedagogical technologies. Karshi: "Nasaf", 2000. - 52 p. 
8. 8.Shomirzaev M.X. Innovative pedagogical technologies in teaching technology. Study guide. -T .: "Tafakkur" 2020. - 226 p.

9. MX Shomirzayev. (2019) Ways to increase the effectiveness of teaching technology. Methodological manual.

10. Shomirzayev, M. K. (2021). Practical lessons in technology: Characteristics of organization and conduct. ASIAN JOURNAL OF MULTIDIMENSIONAL RESEARCH, 10(4), 991-1001.

11. Shomirzayev, M. K. (2021). Combined In Technology Courses Use Of Technologies. The American Journal of Social Science and Education Innovations, 3(05), 389396.

12. Shomirzayev, M. K., \& Yuldashov, K. K. (2021). THE EDUCATIONAL IMPORTANCE OF TEACHING KNOWLEDGE TO SECONDARY SCHOOL STUDENTS. CURRENT RESEARCH JOURNAL OF PEDAGOGICS (2767-3278), 2(08), 132-142.

13. Shomirzayev, M. K. (2021). Developing educational technologiesin school technology education. ASIAN JOURNAL OF MULTIDIMENSIONAL RESEARCH, 10(5), 73-79

14. Shomirzayev, M. K. Technology of Educational Process in School Technology Education. The American Journal of Social Science and Education Innovations. Impact Factor, 5(02), 212223. 